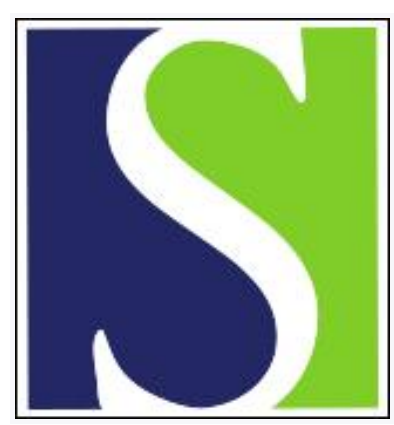

Scand J Work Environ Health 2003;29(1):78-79

https://doi.org/10.5271/sjweh.1020

Issue date: Feb 2003

Evidence-based medicine and evidence-based occupational health

by Franco $G$

Affiliation: Department of Internal Medicine and Medical Specialties, University of Modena and Reggio Emilia, Largo del Pozzo, 71 I - 41100 Modena, Italy. franco@unimo.it

Refers to the following texts of the Journal: 2002;28(3):197-204 2002;28(5):358-359 2002;28(5):359-360

Key terms: evidence-based medicine; evidence-based occupational health; letter to the editor; patient actions; patient preferences; patient values

This article in PubMed: www.ncbi.nlm.nih.gov/pubmed/12630440

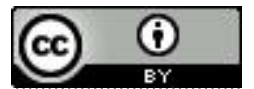




\section{Evidence-based medicine and evidence-based occupational health}

Recently the Scandinavian Journal of Work Environment \& Health published an interesting paper dealing with the evidence-based approach to occupational health problems (1). In the following issue of the Journal a comment appeared (2), together with the reply of the paper's authors stressing the scientific value of the approach (3). Because the application of the principles of evidence-based medicine is new in the field of occupational health, as Verbeek and his colleagues stated, the topic is worthy of being briefly illustrated by pointing out some components of the evidence-based model used for clinical decisions in medicine (4).

This model focuses on expertise, as the pivotal element grouping the other underlying elements: (i) clinical state and circumstances, (ii) patients' preferences and action, and (iii) research evidence. A logical parallelism can be established between each element of the model and elements of occupational health practice. These components are considered separately.

Clinical state and circumstances. The health problem, and the circumstances under which it occurs, are the key factors in the decision process. In the model for evidence-based clinical decisions, the health problem is represented by the individual patient's problem, whereas, in the evidence-based occupational health model, it is represented by an occupational problem requiring attention by competent authorities. This problem can involve a community or an individual (as in the case of workers affected by a disorder caused by their occupational activity or exposure).

As in the model for evidence-based clinical decisions, circumstances are important. In fact, the problem may be differently approached in different countries and settings, depending on the different context and time in which it occurs. The main circumstances relevant to the model include the availability of resources, the sociocultural environment, the local burden of diseases, and the risk factors.

Patients' preferences, values, and actions. In the model for evidence-based clinical decisions, the second element is represented by patients' preferences and actions (ie, the clinician needs to take into account the patients' preferences and which intervention patients are likely to accept). In the evidence-based occupational model this component could be seen as the stakeholders' pref- erences, values, and actions, since interventions cannot be carried out unless stakeholders' needs are met. In fact, patients' care and treatment are the mission of the physician, whereas workers' health protection and promotion are the mission of occupational health professionals. The two-way relationship between patients and physicians represents the backbone of curative practice, whereas multifaceted relationships characterize occupational health practice (5). Several actors claim their right, duty, and professional interest in participating in the decision process leading to action. In a work environment, for example, the occupational health physician has a number of duties if a health problem consisting of the observation of an unexpected cluster of disease occurs. These duties include informing the employer, the company management, the worker representative, the labor inspectorate, the trade union, and, of course, the workers (6). Every action to be taken often needs to be communicated, evaluated, and established together with the other stakeholders, who may participate, modify, and, in any case, contribute or interfere in the decisionmaking process. This process differs from the clinician's action, which may be limited to communication with the patient and the family. This fact leads to a complex relationship system involving stakeholders, which is usually not appreciable in a clinician's practice: each situation requires that several crucial elements be taken into account, in addition to the scientific evidence and assessment of known or potential risk, such as legal requirements, technical feasibility, the benefits and cost within the population and among interested groups, and political and sociocultural commitments.

Research evidence. In comparison with clinical research, the research for evidence in occupational health differs, both in the evidence-searching stage and in the evidence appraisal stage. The model for evidence-based medicine is founded on evidence provided by randomized controlled trials; this body of evidence is often unavailable for actions in the preventive field (studies are not feasible or are unethical). In spite of these problems, the appraisal of research evidence has been suggested in occupational health (1). As in clinical settings, however, evidence alone is not an adequate guide for action; instead evidence for the strength of effectiveness is generally linked to the strength in recommendation, although other items, such as applicability and economic 
evaluation and barriers to implementation, may be considered (7).

Clinical state and circumstances, patients' preferences and action, and research evidence are integrated in the expertise (4). Expertise gains a central role within the model framework: the occupational health physician must have skills to identify the problem in its context correctly, to involve other stakeholders successfully in the decision process, and to find, appraise and apply the evidence in practice.

In conclusion, as clinicians move within a framework of research-informed health care while taking into account the need to satisfy the patient, occupational health practitioners act according to a different but similar model which (i) takes into account the complexity and the context in which the health problem occurs, (ii) emphasizes the linkage with the other stakeholders involved in the solution of the health problem, and (iii) stresses the scientific evidence. These elements can be fruitfully integrated only if consistent expertise in the field is present.

\section{References}

1. Verbeek JH, van Dijk FJ, Malmivaara A, Hulshof CT, Räsänen K, Kankaanpää EE, Mukala K. Evidence-based medicine for occupational health. Scand J Work Environ Health 2002;28:197-204.

2. Larsen AI, Jepsen JR. Evidence in occupational medicine [letter]. Scand J Work Environ Health 2002;28:358-59.

3. Verbeek J, van Dijk F, Malmivaara A, Hulshof C, Räsänen K, Kankaanpää E, Mukala K. Authors' reply [letter]. Scand J Work Environ Health 2002;28:359-360.

4. Haynes RB, Devereaux PJ, Guyatt GH. Physicians' and patients' choices in evidence based practice. BMJ 2002;324: 1350.

5. Franco G. The future of occupational health practice: reconciling customer expectation and evidence-based practice [editorial]. Occup Med 2001;51:482-4.

6. International Labour Office (ILO). Technical and ethical guidelines for workers' health surveillance. Geneva: ILO; 1998. Occupational and health safety series, no 72.

7. Briss PA, Zaza S, Pappaioanou M, Fielding J, Wright-De Aguero L, Truman BI, et al. Developing an evidence-based guide to community preventive services-methods. Am J Prev Med 2000;18(1S):35-43.

Giuliano Franco, MD

Department of Internal Medicine and Medical Specialties University of Modena and Reggio Emilia

Largo del Pozzo, 71

I - 41100 Modena, Italy

[E-mail: franco@unimo.it] 